Personalidade Acadêmica Homenageada:

Augustus B. Cochran III (Agnes Scott College)

\title{
ACESSO À SAÚDE NO BRASIL: O PROGRAMA MAIS MÉDICOS E OS PROBLEMAS PARA EFETIVAÇÃO DA GARANTIA CONSTITUCIONAL
}

\section{HEALTH ACCESS IN BRAZIL: THE MEDICAL PROGRAM AND PROBLEMS FOR THE CONSTITUTIONAL GUARANTEE}

\section{LOURENÇO DE MIRANDA FREIRE NETO}

Doutorando em Direito Político e Econômico pela Universidade Presbiteriana Mackenzie - UPM; Mestre em Direito pela Universidade Católica de Pernambuco. Bacharel em Direito pela Universidade Federal da Paraíba. Professor efetivo na Universidade Federal da Paraíba. Email: lourencomiranda@gmail.com.

\section{PRISCILA LUCIENE SANTOS DE LIMA}

Doutorando em Direito Político e Econômico pela Universidade Presbiteriana Mackenzie - UPM; Mestre em Direito Empresarial e Cidadania do Centro Universitário Curitiba - UNICURITIBA; Especialista em Direito do Trabalho e Processo do Trabalho pela Pontifícia Universidade Católica do Paraná - PUCPR; Bacharel em Direito pela Universidade Tuiuti do Paraná - UTP. Professora e Advogada. Email: pritysantoslima@hotmail.com

\section{RESUMO}

A garantia do acesso à saúde no Brasil é tema recorrente nas discussões sobre os problemas enfrentados pelos cidadãos usuários dos serviços públicos de saúde, razão pela qual é necessário estudar e diagnosticar problemas e as possíveis soluções para os mesmos, no contexto do nosso Sistema Único de Saúde. Um destes problemas tem ganhado grande destaque, a saber, a presença física dos médicos, notadamente 


\title{
Personalidade Acadêmica Homenageada:
}

\section{Augustus B. Cochran III (Agnes Scott College)}

as desigualdades de distribuição dos mesmos, com tentativa de solução adotada pelo Programa Mais Médicos, razão pela qual é mister analisar se tal política pública soluciona a contento a questão, bem como, de forma geral, quais as estratégias complementares ou alternativas a serem implementadas de forma a obter, no maior grau possível, a efetivação da garantia constitucional. Palavras-chave: Acesso à saúde. Políticas públicas em saúde. Programa Mais Médicos.

PALAVRAS-CHAVE: Acesso à Saúde; Mais Médicos; SUS.

\begin{abstract}
The guarantee of access to health in Brazil is a recurring theme in the discussions about the problems faced by citizens who use public health services, which is why it is necessary to study and diagnose problems and possible solutions for them, in the context of our "Sistema Único de Saúde" of these problems has gained prominence, namely the physical presence of physicians, especially the inequalities of their distribution, with an attempt to find a solution adopted by the "Mais Médicos" Program, which is why it is necessary to analyze if such public policy solves to the satisfaction of the question, as well as, in a general way, what complementary or alternative strategies to be implemented in order to obtain, to the greatest possible degree, the realization of the constitutional guarantee. Keywords: Access to health. Public health policies. "Mais Médicos" Program.
\end{abstract}

ABSTRACT: Health Access; More Doctors; SUS.

\section{INTRODUÇÃO}

Apesar das inequívocas e grandes conquistas vivenciadas nos últimos tempos, o cotidiano mostra um total desrespeito com a efetivação de diversas garantias constitucionais. Com uma busca crescente pela concretização dos direitos 


\section{Personalidade Acadêmica Homenageada:}

\section{Augustus B. Cochran III (Agnes Scott College)}

fundamentais, os quais tiveram como marco garantidor no Brasil a promulgação da Constituição Federal de 1988, é preciso refletir como a implementação dessas prerrogativas inerentes a todos os cidadãos tem se dado na prática.

Diante disso, surgem uma série de indagações que precisam ser respondidas: A garantia de acesso à saúde no Brasil é respeitada? Em que medida o Programa Mais Médicos contribui com esta efetivação? Existe um reflexo entre o acesso aos médicos em si e o acesso à saúde? Há alternativa para distribuição dos médicos pelo território nacional?

No Brasil, desde a entrada em vigor da Constituição Federal de 1988, vivenciamos enormes conquistas teóricas, isto é, foi produzido um texto fantástico e temos uma Carta Magna repleta de importantes direitos e garantias. Por outro lado, quando fazemos um paralelo entre o que está escrito com o que é vivido no cotidiano, enxergamos grandes distorções. E dentre os casos mais patentes e graves, estão as garantias dos acessos à saúde e à justiça, diuturnamente feridas e relegadas.

Cada uma dessas garantias ofendidas possuem particularidades e minúcias que levam ao impedimento de sua fruição pelos cidadãos, grande parte por problemas afeitos ao Estado Brasileiro e sua incapacidade em prover serviços públicos de qualidade.

Objetivamos, portanto, de forma geral, expor o grave problema de efetivação das garantias fundamentais, notadamente do acesso à saúde, no Brasil. Especificamente, buscamos refletir sobre o Programa Mais Médicos, analisando se a política pública produz efetividade à garantia constitucional, bem como, se é o instrumento mais eficaz para alcançar o resultado pretendido.

Realizaremos uma pesquisa qualitativa, focada no estudo dos problemas para acesso à saúde, por meio do aprofundamento da compreensão dos mesmos, que, por sua vez, não podem ser quantificados, mas tão somente explicados, no contexto da dinâmica das relações sociais, muito embora elementos quantitativos acerca da implementação do Programa Mais Médicos igualmente serão analisados.

Ademais, ao buscarmos distinguir os fatores que influem na ocorrência dos fenômenos problemáticos descritos, produzimos uma pesquisa explicativa, de procedimento ex-post-facto, tendo em vista o estudo das relações de causa e efeito 


\section{Personalidade Acadêmica Homenageada:}

\section{Augustus B. Cochran III (Agnes Scott College)}

vistas entre o acesso ao profissional médico e o acesso à saúde em si. Por outro lado, ao esmiuçarmos os problemas, buscando maior familiaridade para construir referida hipótese, também utilizamos uma base exploratória, de procedimento eminentemente bibliográfico e documental.

Além disso, adotamos como método de abordagem o indutivo, com a observação do fenômeno particular, isto é, o Programa Mais Médicos, a descoberta de uma relação de causa entre ele e o acesso à saúde com, ao cabo, a generalização da relação, ou seja, como a implementação da política pública interfere na efetivação daquele direito basilar, bem como, se há uma política alternativa que possa garantir a efetivação da garantia constitucional de modo menos gravoso.

\section{ACESSO À SAÚDE NO BRASIL: O DIREITO FUNDAMENTAL BASE DA POLÍTICA PÚBLICA E O CAMINHO ATÉ O SISTEMA ÚNICO DE SAÚDE}

O direito à saúde se constitui um verdadeiro direito fundamental. A necessidade de saúde é algo inerente a todo indivíduo, sendo claramente universal. Historicamente, tal garantia está ligada ao ideal de perpetuação da espécie humana e aversão à morte. No atual momento, notabiliza-se pela busca cada vez maior por vida longeva e plena, não sendo, de forma alguma, um bem possível de disponibilização, por ser um atributo umbilicalmente ligado à dignidade humana.

Assim, seu ingresso no vigente ordenamento jurídico constitucional brasileiro se deu, dentre outros, por meio do artigo 197 da Constituição Federal de 1988, o qual assevera:

A saúde é direito de todos e dever do Estado, garantido mediante políticas sociais e econômicas que visem à redução do risco de doença e de outros agravos e ao acesso universal e igualitário às ações e serviços para sua promoção, proteção e recuperação.

Portanto, resta claro que a garantia do acesso à saúde se notabiliza como um direito eminentemente fundamental, razão pela qual se encontra previsto 


\section{Personalidade Acadêmica Homenageada:}

\section{Augustus B. Cochran III (Agnes Scott College)}

constitucionalmente e obriga os poderes públicos a concretizarem-no. Logo, está sistematizado em mecanismos de proteção e de (tentativa de) efetivação nos ordenamentos jurídicos nacional, ocorrido após longa construção histórica. A saúde pública brasileira evoluiu bastante ao longo de nossa história, até culminar com a criação do atual modelo, que tem como base o intitulado "Sistema Único de Saúde", surgido a partir da redemocratização e da Constituição Federal de 1988.

No período do colonialismo português, entre os anos de 1500 e 1822, prevalecia um contexto econômico de exploração de matérias primas e um forte controle comercial, social, político e cultural, por parte de Portugal. A organização sanitária era, portanto, bastante precária ou quase inexistente. Com o estabelecimento da família real no Brasil, tivemos a criação, na Bahia, do Colégio Médico - Cirúrgico do Real Hospital Militar da Cidade de Salvador, e, no Rio de Janeiro, da Escola de Cirurgia do Rio de Janeiro, ambos em 1808. A assistência vinha, ainda, por meio de alguns hospitais das Santas Casas de Misericórdia em Santos, São Paulo, Salvador, Rio de Janeiro, Belém e Olinda, sem, no entanto, haver qualquer estruturação/planejamento de um modelo geral de gestão sanitária. (SINGER et al, 1988)

O Período Imperial, vivido após a independência do Brasil, entre os anos de 1822 e 1889, trouxe um fato marcante com reflexos na saúde, o crescimento do comércio e da industrialização global, culminando com uma maior abertura de portos. Assim, foram criadas, no plano nacional, as primeiras organizações para controle sanitário, relacionadas diretamente aos portos, em 1828 e, posteriormente, ao controle de epidemias, em 1850. Além disso, como o sistema político tinha como base a política local do coronelismo, desenvolveu-se também um modelo municipalista de saúde, construído e administrado de forma heterogênea, em cada localidade específica. (MACHADO et al, 1978)

A partir da República Velha, período que vai de 1889 a 1930, começou-se a se estruturar um sistema de saúde mais organizado, tendo em vista os inúmeros problemas sociais gerados pelo incipiente modelo sanitário existente até então. Desta feita, em 1897, foi criada a Diretoria Geral de Saúde Pública, assumida por Oswaldo Cruz. As reformas implementadas possibilitaram um registro demográfico para 


\section{Personalidade Acadêmica Homenageada:}

\section{Augustus B. Cochran III (Agnes Scott College)}

diagnosticar a situação da população, a inserção do laboratório como auxiliar nos diagnósticos e a produção organizada de meios profiláticos para uso em massa, notadamente das vacinas. (BRAGA; PAULA, 1986)

Além disso, Carlos Chagas, sucessor de Oswaldo Cruz, ampliou as conquistas com um modelo de educação sanitária e expandindo o saneamento pelo país. No período, tivemos ainda a criação das Caixas de Aposentadoria e Pensão (CAP's), por meio da chamada Lei Eloy Chaves. Essas entidades, criadas para atender os anseios sociais dos trabalhadores urbanos, eram instituídas pelas empresas, com seu financiamento próprio, juntamente com seus funcionários e consumidores. Além de pagamento de aposentadoria e pensões, as CAP's proviam o custeio de cuidados médicos, fazendo nascer uma simbiose entre os sistemas de previdência social e de saúde. (POSSAS, 1981)

Na Era Vargas, entre 1930 e 1945, as CAP's foram substituídas pelos Institutos de Aposentadorias e Pensões (IAP's), organizado por categorias profissionais e não mais por empresas, disseminando o modelo para vários grupos de trabalhadores, que teriam o adimplemento de despesas médicas. Além disso, criouse o Ministério da Educação e Saúde Pública, juntamente com medidas de fiscalização de produtos animais no Ministério da Agricultura e de higiene e segurança do trabalho, por meio do Ministério do Trabalho. Ademais, com a reforma Barros Barreto, instituiu-se órgãos executivos, normativos e supletivos de assistência médicohospitalar, com o fortalecimento do Instituto Oswaldo Cruz, criaram-se de serviços especializados de abrangência nacional, como o Instituto Nacional do Câncer, e ampliou-se o abastecimento de água e o esgotamento sanitário. (FONSECA, 2007)

Com a chegada dos Governos Populistas, nos anos de 1945 a 1964, foi criado o Ministério da Saúde, com um desmembramento do Ministério da Educação. Outro ponto importante foi a edição da Lei Orgânica da Previdência Social, que universalizou o acesso ao regime geral da previdência social para todos os trabalhadores urbanos e rurais, estes últimos posteriormente, por meio da criação do Fundo de Assistência do Trabalhador Rural. Logo, o custeio de amparo médico foi ampliado consideravelmente, fazendo surgir empresas de saúde e expandindo a assistência hospitalar. (DONNANGELO, 1975) 


\section{Personalidade Acadêmica Homenageada:}

\section{Augustus B. Cochran III (Agnes Scott College)}

A ditatura militar, instaurada entre 1964 e 1985, unificou os Institutos de Aposentadorias e Pensões, o Serviço de Assistência Médica e Domiciliar de Urgência (SAMDU) e a Superintendência dos Serviços de Reabilitação da Previdência Social em um órgão único, o Instituto Nacional de Previdência Social (INPS), que passou a contar com vultosa quantidade de recursos. Assim, como o sistema de saúde estatal existente não era capaz de suprir a demanda, houve direcionamento de serviços de saúde para a iniciativa privada, por meio de convênios e contratos, os quais, pela grande quantidade, foram administrados por uma estrutura própria, o Instituto Nacional de Assistência Médica da Previdência Social (INAMPS). Em razão disso, houve intenso crescimento de atenção médica, por meio de prestadores privados, com foco na medicina curativa. Foi criado, ainda, em 1975, o Sistema Nacional de Saúde, com o intuito de organizar o campo de atuação dos atores públicos e privados e sistematizar o acesso à saúde. (ESCOREL, 1998)

$\mathrm{Na}$ transição democrática, o modelo privatista sofreu contenção, com a criação das Ações Integradas de Saúde, um projeto que englobava os ministérios da Previdência, da Saúde e da Educação e incorporava fortemente o setor público, na implementação de políticas de saúde curativa, preventiva e educativa simultaneamente. Posteriormente, foram lançadas as bases do Sistema Único Descentralizado de Saúde (SUDS). (TEIXEIRA, 1988)

$O$ ingresso pleno na redemocratização veio com a Constituição Federal de 1988. A Carta Magna ditou as novas bases do nosso modelo sanitário, instituindo o Sistema Único de Saúde, por meio do seguinte artigo:

\footnotetext{
Art. 198. As ações e serviços públicos de saúde integram uma rede regionalizada e hierarquizada e constituem um sistema único, organizado de acordo com as seguintes diretrizes: I - descentralização, com direção única em cada esfera de governo; II - atendimento integral, com prioridade para as atividades preventivas, sem prejuízo dos serviços assistenciais; III participação da comunidade.
}

Por sua vez, em 1990, as Leis 8.080 e 8.142, chamadas de Leis Orgânicas da Saúde, regulamentaram o Sistema Único de Saúde no nosso ordenamento jurídico infraconstitucional. Note-se que, em se tratando de políticas públicas, conforme 


\section{Personalidade Acadêmica Homenageada:}

\section{Augustus B. Cochran III (Agnes Scott College)}

determina a Constituição, as ações agora são pautadas pela descentralização, pelo atendimento integral e pela participação da comunidade.

O primeiro aspecto é reflexo de uma repactuação federativa, com a tentativa de retirar os Estados e os municípios do papel de meros coadjuvantes, trazendo-os para o protagonismo, lado a lado com a União.

$\mathrm{O}$ atendimento integral, por sua vez, preconiza uma assistência total e universal na busca do restabelecimento da saúde, trata-se de um modelo de garantia de vida saudável, não mais de mera cura de doenças, logo, com foco na medicina preventiva, sem qualquer restrição quanto aos titulares desse atendimento. Portanto, - SUS engloba também questões envolvendo meio ambiente, vigilância sanitária, fiscalização de alimentos, dentre outras enumeradas no artigo 200 da Constituição Federal.

Como terceiro ponto, a participação da comunidade vem como corolário das intensas lutas sociais vividas no país, e insere os cidadãos como participantes ativos na construção do sistema de saúde e da própria prevenção, diagnóstico e tratamento das enfermidades.

Desta feita, seguindo esses princípios, foi criado o Programa de Saúde da Família. A integração dos profissionais que compõem as equipes do Programa basicamente médicos, enfermeiros, auxiliares de enfermagem e agentes de saúde com a comunidade e as famílias atendidas vem por meio da atuação em regiões geograficamente delimitadas e com populações específicas. (GIRARDI et al, 2010)

Assim, a chamada atenção primária tem tido nítida evolução e funcionado na redução da mortalidade infantil e de internações hospitalares, sendo serviço de referência para uso habitual por $57 \%$ (cinquenta e sete por cento) da população em 2008, contra $42 \%$ (quarenta e dois por cento) em 1998. (ALMEIDA et al, 2010)

Por outro lado, a despeito de pontuais conquistas, nosso paradigma de assistência à saúde ainda é bastante inócuo, com problemas que envolvem subfinanciamento e estrutura precária, com reflexos sobretudo nas atenções secundária (prestação de serviços especializados), terciária (procedimentos de alto custo) e hospitalar, além de desigualdades regionais e carência de profissionais, estes últimos objetos de estudo deste trabalho e foco do Programa Mais Médicos. 


\section{Personalidade Acadêmica Homenageada:}

\section{Augustus B. Cochran III (Agnes Scott College)}

Convém ressaltar, ainda, que o nosso sistema apesar do predomínio público, é heterogêneo, isto é, composto de uma parte pública e outra parte privada. No setor público, os serviços são financiados pelas três esferas estatais, federal, estadual e municipal; no setor privado, os recursos advém da iniciativa privada ou do Poder Público; há, outrossim, o setor da saúde suplementar, onde vigoram planos privados de assistência à saúde e apólices de seguro-saúde, este último, apesar de regulado pela Agência Nacional de Saúde Suplementar - ANS, repleto de dificuldades.

No entanto, como há notória hegemonia dos prestadores de serviços públicos, financiados com recursos dos tributos, nosso modelo é tido como um sistema universalista, de acesso geral, irrestrito e igualitário, conforme explicitado na nossa Constituição Federal de 1988 e nas Leis Orgânicas da Saúde.

Ademais, importa salientar que nosso Sistema foi montado com inspiração no sistema britânico. O British Nacional Health System - NHS foi implantado na GrãBretanha originalmente em 1948, prevendo assistência universal, integral e equânime. Sua figura central eram os general practitioners (GP's), médicos que atuavam na atenção básica primária, recebendo seu pagamento por paciente integrante de seu portfólio. A população era orientada a se vincular a apenas um profissional específico que, a partir daí, iria prestar pessoalmente àquele cidadão serviços ambulatoriais e assistência médica não-emergencial. (KOEN, 2000)

Desta feita, o Sistema Único de Saúde brasileiro tem também como figura central o médico generalista, que servirá como porta de entrada e importante filtro a manter o sistema de acesso à saúde. Assim, sua presença nas mais diversas localidades de um país com dimensões continentais é fundamental para efetivação da garantia, muito embora constitua um grande desafio de política pública, sendo assim, foi criado, em 2013, o Programa Mais Médicos, instrumento que passaremos a analisar. 


\section{Personalidade Acadêmica Homenageada:}

\section{Augustus B. Cochran III (Agnes Scott College)}

\section{O PROGRAMA MAIS MÉDICOS: A POLÍTICA PÚBLICA E SEUS PROBLEMAS}

\subsection{DESENHO GERAL DA POLÍTICA PÚBLICA}

É cediço que o Programa Mais Médicos é corolário da garantia constitucional do acesso à saúde, especialmente do que preconizam os artigos 194 e 196 da Constituição Federal de 1988, com expressos direitos à universalidade da cobertura e do atendimento, à uniformidade e equivalência dos benefícios e serviços às populações urbanas e rurais, à seletividade e distributividade na prestação dos benefícios e serviços, isto é, ao acesso universal e igualitário às ações e serviços para promoção, proteção e recuperação da saúde como direito de todos e dever do Estado.

A escassez de médicos ainda é um grande gargalo na expansão da atenção básica de saúde, bem como sua desigual distribuição, razão pela qual foi estruturada uma política pública através da MEDIDA PROVISÓRIA № 621, de 8 de julho de 2013, convertida na LEI № 12.871, de 22 de outubro de 2013 que instituiu uma política pública mais ampla acerca da formação médica e, especificamente, criou e dispôs sobre o Projeto Mais Médicos para o Brasil, em seus artigos 13 a 22. Em especial, destaca-se o artigo 16, que dispõe:

Art. 16. O médico intercambista exercerá a Medicina exclusivamente no âmbito das atividades de ensino, pesquisa e extensão do Projeto Mais Médicos para o Brasil, dispensada, para tal fim, nos 3 (três) primeiros anos de participação, a revalidação de seu diploma nos termos do $\S 2^{\circ}$ do art. 48 da Lei oํ 9.394, de 20 de dezembro de 1996.

Na ocasião, a proporção de médicos era de 1,8 por mil habitantes, a meta do Programa é chegar aos 2,7 profissionais por mil habitantes até 2026, referência utilizada a partir da realidade do Reino Unido, que conta com sistema universal semelhante ao nosso Sistema Único de Saúde. Em janeiro de 2018, esta proporção subiu para 2,18 médicos por mil habitantes. O Programa acrescentou, portanto, 18.240 (dezoito mil duzentos e quarenta) profissionais distribuídos entre $81 \%$ dos municípios brasileiros (BRASIL, 2015). 
DOI:

\section{Personalidade Acadêmica Homenageada:}

Augustus B. Cochran III (Agnes Scott College)

As prefeituras municipais foram convocadas a aderirem ao Programa, mediante Termo em que teriam médicos disponibilizados para atendimento à população local, com o compromisso de não reduzirem o seu quadro de profissionais já atuantes. Nos Municípios que aderiram ao Programa, o número de médicos saltou de 46.674, em 2011, para 54.525, em 2015; já nos Municípios que não aderiram, o crescimento foi de 6.918, em 2011, para 7.385, em 2015.

A construção foi inspirada e tem a colaboração da Organização PanAmericana da Saúde, órgão vinculado à Organização Mundial da Saúde da Organização das Nações Unidas, entidade que coopera com os países nos preparativos para situações de emergência e na coordenação de socorro em casos de desastres, além de atuar através da elaboração de planos nacionais de emergência e de planos regionais de investimentos em saúde, notadamente com o envio de profissionais de saúde, para atendimento em situações excepcionais. Tal parceria, conforme dados do Tribunal de Contas da União (BRASIL, 2017), resultou em uma execução de $R \$ 3,77$ bilhões no triênio 2013-2015, especificamente no que se refere ao Termo de Cooperação Internacional nํ. 80 celebrado com a Organização Panamericana da Saúde-OPAS/OMS (R $\$ 3,67$ bilhões) - destinado ao custeio das despesas relativas aos médicos cubanos, ao pagamento de bolsas-formação ( $R \$ 54$ milhões) e de ajuda de custo ( $R \$ 38,4$ milhões) aos médicos brasileiros e aos intercambistas individuais, recursos esses oriundos da Diretoria - Executiva do Fundo Nacional de Saúde, da Coordenação-Geral de Pessoas e da Coordenação-Geral de Material e Patrimônio, do Ministério da Saúde.

Por sua vez, houve oposição da classe médica com o argumento dos riscos ao atendimento da população pela suposta má-formação dos médicos integrantes do Programa, considerando não terem se submetido à prova de revalidação de seus diplomas, o REVALIDA. A estratégia de oposição a este argumento foi prevista na política quando a distribuição das vagas para atuação dos médicos obedeceu ao preenchimento prioritário por médicos com registro regular nos Conselhos de Medicina e, apenas as vagas não preenchidas por estes profissionais, seriam ofertadas aos denominados médicos intercambistas, prioritariamente brasileiros formados no exterior e excepcionalmente estrangeiros, os quais passaram a atuar em 


\section{Personalidade Acadêmica Homenageada: \\ Augustus B. Cochran III (Agnes Scott College)}

áreas em que a população ficaria desassistida. Ocorre que, como veremos, os Editais lançados acabaram por não pôr em prática de maneira efetiva esta regra.

Com relação à distribuição de médicos no país, conforme dados da "Demografia Médica 2018", o país contava, em janeiro de 2018, com 452.801 médicos (razão de 2,18 médicos por mil habitantes), contra 364.757 de 2010 (razão de 1,91 por mil habitantes). O Sudeste é a região com maior densidade médica por habitante, com razão de 2,81, contra 2,36 do Centro-Oeste, 2,31 do Sul, 1,41, no Nordeste, e 1,16 , no Norte. Somente o estado de São Paulo concentra $21,7 \%$ da população total e $28 \%$ do total de médicos do país. Por sua vez, o Distrito Federal tem a razão mais alta, com 4,35 médicos por mil habitantes, seguido pelo Rio de Janeiro, com 3,55. Na outra ponta estão estados do Norte e Nordeste. O Maranhão mantém a menor razão entre as unidades federativas, com 0,87 médico por mil habitantes, seguido pelo Pará, com razão de 0,97. Vê-se, portanto, a perpetuação da má-distribuição e desigualdades regionais.

Por outro lado, sabemos que bem jurídico protegido com a implantação da política pública é o acesso à saúde, especificamente o acesso da população de regiões remotas aos profissionais médicos. Para tanto, abriu-se mão de uma maior segurança e controle da formação profissional dos agentes que ingressam no mercado de trabalho nesta profissão que tem a aptidão para causar um dano social enorme, com risco à vida dos cidadãos, caso não haja a devida regulamentação no ingresso desses profissionais na carreira. Além disso, há que se verificar se apenas esta ação de expansão dos profissionais é suficiente para efetivar o acesso à saúde nessas regiões onde há deficiência de médicos ou se há necessidade de criação de outras estratégias. Nesse sentido, em estudo de Pereira et al (2015):

Percebeu-se que a presença de médicos na atenção primária é essencial na prestação de cuidados de forma continuada aos usuários e suas famílias, e que tem importante impacto na sua saúde e no funcionamento dos serviços. A permanência de tais profissionais facilita a criação de vínculo com as comunidades, contribuindo para a compreensão dos processos de saúde e doença, bem como seus determinantes, auxiliando na formulação de estratégias mais adequadas às necessidades da população. Destaca-se, no entanto, a necessidade da formulação de políticas e ações voltadas a efetivação do SUS em longo prazo, principalmente no que diz respeito à melhoria das condições de trabalho e de infra-estrutura, expansão de 


\title{
Personalidade Acadêmica Homenageada:
}

\section{Augustus B. Cochran III (Agnes Scott College)}

\begin{abstract}
contratações de profissionais para compor as equipes de saúde, criação de planos de carreira para os profissionais, e a priorização da atenção primária, focando no fortalecimento da prevenção e na promoção da saúde.
\end{abstract}

Sendo assim, é possível que existam meios menos gravosos para obter a mesma proteção desejada, especialmente por meio de Propostas de Emenda à Constituição, em tramitação no Congresso Nacional, que prevêem a implantação da carreira médica nacional, apta a contratar profissionais por meio de concurso público e fixa-los obrigatoriamente em regiões mais longínquas, garantindo um plano de cargos e carreira em que possa ter mobilidade para regiões centrais ao longo da carreira, de maneira semelhante ao que ocorre com a Magistratura. Outra estratégia, por exemplo, verifica-se na Austrália, em que a remuneração dos médicos que integram o programa Overseas Training Doctors varia de acordo com a região, sendo maior em zonas mais remotas

\subsection{DIAGNÓSTICO DOS PROBLEMAS}

\subsubsection{Regulamentação das Profissões, Segurança Social e Critérios de Habilitação}

A primeira objeção que se pode apontar à adoção da política pública envolve a própria razão de ser da regulamentação das profissões, a segurança social daí advinda, por meio do estabelecimento de critérios de habilitação para que os variados profissionais exerçam os seus misteres no mercado.

A Constituição Federal, no inciso XIII, do artigo 5으, garante ser "livre o exercício de qualquer trabalho, ofício ou profissão", desde que "atendidas as qualificações profissionais que a lei estabelecer". Logo, a princípio, o exercício será livre, cabendo à legislação o regulamento de determinadas atividades, isto é, justamente as que tem potencial de causar um maior dano social, razão pela qual seu exercício não pode permanecer liberado de maneira irrestrita.

No caso da Medicina, tal regulamentação é dada pelas Leis $n .$. 12.842/2013, ก.ํ 3.268/1957, e pelo o Decreto-lei n.. 44.045/1958. O Diploma Legal de 1957 já deixa claro que: 


\title{
Personalidade Acadêmica Homenageada: \\ Augustus B. Cochran III (Agnes Scott College)
}

\begin{abstract}
Art. 17. Os médicos só poderão exercer legalmente a medicina, em qualquer de seus ramos ou especialidades, após o prévio registro de seus títulos, diplomas, certificados ou cartas no Ministério da Educação e Cultura e de sua inscrição no Conselho Regional de Medicina, sob cuja jurisdição se achar o local de sua atividade.
\end{abstract}

Tal fato se justifica, como dito, dado o potencial impacto social que o exercício de tal atividade pode ocasionar, considerando que, nos termos da legislação de 2013:

\begin{abstract}
Art. 4. ${ }^{\circ}$ São atividades privativas do médico: I - (Vetado.); II - indicação e execução da intervenção cirúrgica e prescrição dos cuidados médicos pré e pós-operatórios; III - indicação da execução e execução de procedimentos invasivos, sejam diagnósticos, terapêuticos ou estéticos, incluindo os acessos vasculares profundos, as biópsias e as endoscopias; IV - intubação traqueal; V - coordenação da estratégia ventilatória inicial para a ventilação mecânica invasiva, bem como das mudanças necessárias diante das intercorrências clínicas, e do programa de interrupção da ventilação mecânica invasiva, incluindo a desintubação traqueal; VI - execução de sedação profunda, bloqueios anestésicos e anestesia geral; VII - emissão de laudo dos exames endoscópicos e de imagem, dos procedimentos diagnósticos invasivos e dos exames anatomopatológicos; VIII - (Vetado.); IX - (Vetado.); $\mathrm{X}$ - determinação do prognóstico relativo ao diagnóstico nosológico; XI indicação de internação e alta médica nos serviços de atenção à saúde; XII realização de perícia médica e exames médico-legais, excetuados os exames laboratoriais de análises clínicas, toxicológicas, genéticas e de biologia molecular; XIII - atestação médica de condições de saúde, doenças e possíveis sequelas; XIV - atestação do óbito, exceto em casos de morte natural em localidade em que não haja médico.Os médicos só poderão exercer legalmente a medicina, em qualquer de seus ramos ou especialidades, após o prévio registro de seus títulos, diplomas, certificados ou cartas no Ministério da Educação e Cultura e de sua inscrição no Conselho Regional de Medicina, sob cuja jurisdição se achar o local de sua atividade.
\end{abstract}

Como lembra Genival Veloso de França (2017, p. 50): "Em 1335, na França, João I restringiu o exercício da profissão médica aos licenciados nas Universidades. Daí em diante, em vários países da Europa, só se permitia a prática da profissão àqueles que possuíssem um curso médico."

É certo que o Programa estabeleceu alguns critérios mínimos de habilitação e acompanhamento, no entanto, bem mais frágeis que a legislação regulamentar da profissão e de difícil acompanhamento pelas autoridades nacionais, resultando, conforme achados do Tribunal de Contas da União, no fato de "médicos intercambistas que estavam em atividade à época da auditoria, embora devessem ter 


\section{Personalidade Acadêmica Homenageada: \\ Augustus B. Cochran III (Agnes Scott College)}

sido reprovados, fizeram recuperação de forma irregular ou não a fizeram quando deveriam ter feito" (BRASIL, 2015).

\subsubsection{Substituição de Médicos Contratados por Intercambistas, Preterição de Médicos} Brasileiros e Tratamento Anti-isonômico aos Intercambistas Cubanos

A política pública tem previsão de preferência para ocupação das vagas por médicos brasileiros formados no país, ou seja, registrados no respectivo Conselho Regional de Medicina. Ocorre que, tal premissa não foi suficiente para evitar a preterição de médicos brasileiros ou sua substituição por intercambistas.

Com a implantação da política com custeio federal, é natural imaginar que as prefeituras municipais, em grande parte sofrendo com carência de recursos, substituísse os médicos brasileiros contratados regularmente, por médicos componentes do Programa, tal fato não foi monitorado, conforme atesta o Tribunal de Contas da União:

Constatou-se que não houve uma avaliação para checar se os municípios substituíram médicos que compunham anteriormente as equipes de atenção básica por médicos participantes do Projeto. Também não foi verificado se houve redução do número de equipes constituídas. (BRASIL, 2015)

Desta feita, há fortes indícios de que a adoção da política acabou por gerar uma troca de médicos regularmente contratados pelas edilidade municipais, por profissionais do Programa, conforme se depreende dos dados colhidos pelo Tribunal de Contas da União:

- em 161 desses municípios (14\% da amostra), houve redução do número de médicos; - em outros 239 municípios ( $20 \%$ da amostra), não houve nem aumento nem redução do número de médicos, mesmo após a chegada dos novos profissionais, o que é um forte indício de que houve a substituição dos médicos contratados anteriormente pelos municípios por profissionantes que participam do Projeto Mais Médicos; - em 168 municípios (14\% da amostra), houve aumento na quantidade de médicos, mas esse aumento foi inferior ao número de médicos recebidos por meio do Projeto Mais Médicos (substituição parcial); - em 268 municípios ( $23 \%$ da amostra) o incremento de médicos foi exatamente igual à quantidade de médicos recebidas pelo Projeto; - em outros 268 municípios ( $23 \%$ da amostra) houve um aumento do número de 
DOI:

\title{
Personalidade Acadêmica Homenageada: \\ Augustus B. Cochran III (Agnes Scott College)
}

médicos em quantidade superior à de médicos recebidos; - em 70 municípios (6\% da amostra), foi impossível fazer essa análise, pois as bases de dados encontravam-se incompletas; (BRASIL, 2015)

Ademais, é possível verificar nos editais publicados para adesão, que os candidatos deveriam optar pelos possíveis Municípios de atuação, em ordem de até 4 (quatro) localidades, dentro de 8 (oito) perfis. Logo, ao indicar suas prioridades sem êxito, há cômputo de tais vagas como remanescentes, com o consequente preenchimento das mesmas pelos demais profissionais, isto é, formados no exterior, inicialmente brasileiros e, posteriormente, estrangeiros, sem que sejam dadas novas oportunidades de aceite aos médicos brasileiros formados no país, como demonstra o Edital n‥ 12, de 27 de novembro de $2017^{1}$.

Solução diversa foi adotada no recente Edital n‥ 18, de 19 de novembro de $2018^{2}$, que teve alocação praticamente integral de médicos brasileiros formados no país, o que demonstra claros indícios de preterição, por meio do mecanismo adotado pelos editais anteriores.

Saliente-se, ao cabo, que mesma análise do Tribunal de Contas da União, ainda constatou, especificamente sobre os profissionais de Cuba:

\begin{abstract}
- desigualdade indevida de tratamento entre os profissionais cubanos e os naturais de outros países; - discrepância entre os dispêndios do governo brasileiro e a remuneração paga a título de bolsa para o profissional de origem cubana; - existência de restrição às liberdades individuais dos profissionais cubanos integrantes do programa em foco; - participação de empresa cubana na intermediação da contratação dos profissionais cubanos, desvirtuando os objetivos que fundamentam os projetos de cooperação técnica internacional. (BRASIL, 2015)
\end{abstract}

\footnotetext{
${ }^{1}$ No item 6.7. consta: "Será oportunizada, através do sistema eletrônico (SGP), aos médicos do item 6.6 a indicação de até 4 (quatro) localidades de quaisquer dos perfis de Municípios ofertados, obedecendo ao constante no subitem 6.11 do presente Edital, sendo necessário que o médico indique a ordem de preferência entre as localidades escolhidas, dentro do prazo estabelecido no cronograma." 2 De forma diversa, o novo Edital passou a prever que: "3.2.1. Após a confirmação da inscrição, o SGP disponibilizará a tela para escolha do Município/DSEl para alocação. 3.2.2. O candidato poderá escolher o município/DSEI para alocação, de imediato, após confirmação de inscrição, ou a qualquer momento dentro do período indicado no cronograma disponível no endereço eletrônico http://maismedicos.gov.br. 3.2.3. O direito à alocação se dará pelo critério de prioridade no acesso ao SGP e confirmação da escolha do Município/DSEl, gerando o comprovante de alocação e emitido o Termo de Adesão e Compromisso, conforme minuta do Anexo I. O interessado que primeiro efetivar eletronicamente a opção pelo Município/DSEI terá direito à vaga, estando automaticamente alocado."
} 


\title{
Personalidade Acadêmica Homenageada:
}

\section{Augustus B. Cochran III (Agnes Scott College)}

Logo, por fim, importa pontuar que a política impôs tratamento anti-isonômico aos médicos intercambistas cubanos, contratados por meio de Termo de Cooperação firmado com a Organização Pan-Americana de Saúde (Opas).

\subsubsection{Infraestrutura Precária das Unidades de Saúde e Manutenção das} Desigualdades Regionais na Distribuição dos Profissionais

É certo que buscar a efetivação do acesso à saúde não passa apenas pela presença de profissionais, mas também pela garantia de uma infraestrutura básica para atuação dos mesmos, sob pena da manutenção da falta de atenção à saúde daquelas comunidades. Sobre o tema, pesquisa recente aponta que não houve grandes evoluções neste aspecto:

\begin{abstract}
A infraestrutura frágil e a insuficiência de recursos materiais foram uma realidade constatada no cenário avaliado, também verificada nos cuidados primários de saúde no Brasil. As inadequações das unidades de saúde prejudicam o desenvolvimento das ações na $A B$, a qualidade do cuidado e geram insatisfação nos profissionais e nos usuários. E limitam o potencial dos serviços para a consolidação da ESF, na perspectiva da reorganização de práticas centradas na tríade indivíduo-família-comunidade e na qualidade da atenção à saúde. (MOREIRA et al, 2017)
\end{abstract}

Sendo assim, há que se inserir em uma política pública como a em comento, uma preocupação constante com o avanço da infraestrutura, e não apenas nos recursos humanos. Além disso, é possível perceber que o Programa não foi capaz de solucionar uma das principais razões de sua implantação, a saber, a redução das desigualdades regionais na distribuição dos profissionais. Segundo o Tribunal de Contas da União: "592 dos municípios listados (...), considerados prioritários por serem carentes, não haviam recebido nenhum médico do projeto, o que equivale a $26 \%$ dos municípios dessa relação (592 de 2.282)." (BRASIL, 2015)

Desta feita, é perceptível que a política pública em comento é incapaz de, por si só, promover a efetivação do acesso à saúde no Brasil e, mesmo no que se propõe, mostrou-se inadequada, razão pela qual se torna necessário pensar em outras alternativas para solução do problema social em questão. 


\title{
Personalidade Acadêmica Homenageada: \\ Augustus B. Cochran III (Agnes Scott College)
}

\section{CARREIRA MÉDICA DE ESTADO: UMA ALTERNATIVA}

\author{
Tramita na Câmara dos Deputados Proposta de Emenda à Constituição \\ 454/09, bem como, no Senado Federal a Proposta de Emenda à Constituição \\ 140/2015, ambas com o objetivo de instituir a denominada "carreira médica de \\ Estado", como mecanismo de fixação e distribuição dos médicos pelo território \\ nacional.
}

Tal instituição se daria, conforme a Proposta em tramitação no Senado Federal por meio do acréscimo à Constituição Federal do Artigo 197-A, que teria a seguinte redação:

Art. 197-A. No serviço público federal, estadual e municipal a medicina é privativa dos membros da carreira única de médico de Estado, organizada e mantida pela União, observados os seguintes princípios e diretrizes: I - a atividade de médicos de Estado, exercida por ocupantes de cargos efetivos, cujo ingresso na carreira dar-se-á mediante concurso público de provas e títulos, terá a participação do respectivo órgão de fiscalização profissional; II - o médico de Estado exercerá seu cargo em regime de dedicação exclusiva e não poderá exercer outro cargo ou função pública, salvo uma de magistério, na forma desta Constituição; III - a ascensão funcional do médico de Estado far-se-á, alternadamente, pelos critérios de antiguidade e merecimento, considerando-se, para a aferição do merecimento, quesitos que levem em consideração o aperfeiçoamento profissional do médico, conforme normas estabelecidas pela Associação Médica Brasileira e pelo Conselho Federal de Medicina, na forma da lei; IV - a lei estabelecerá critérios objetivos de lotação e remoção dos médicos de Estado, segundo a necessidade do serviço e considerando, para a elaboração dos requisitos de remoção, a pontuação por lotação em localidades perigosas, remotas, ou de difícil acesso; $V$ - o médico de Estado não poderá, a qualquer título ou pretexto, receber honorários, tarifas ou taxas, auxílios ou contribuições de pessoas físicas ou jurídicas, públicas ou privadas, nem participar do produto da sua arrecadação, ressalvadas as exceções previstas em lei. VI - o exercício administrativo e funcional do cargo de médico de Estado será, na forma da lei, regulado e fiscalizado por órgão colegiado que, com funções exclusivas de normatização, de correição funcional e de ouvidoria, compor-se-á paritariamente por médicos de Estado eleitos pela carreira, por representantes da sociedade civil não pertencentes à categoria médica e representantes do Ministério da Saúde. VII - os médicos federais, estaduais e municipais concursados pelas regras anteriores à promulgação desta Emenda à Constituição, constituirão carreira em extinção, sendo-lhes ressalvado o direito de migração para a carreira de Médico de Estado, conforme estabelecido em lei de âmbito nacional. VIII - a remuneração da carreira do médico de Estado valorizará o tempo de serviço e os níveis de qualificação na área médica e terá seu piso profissional nacional fixado por lei. IX - o disposto no artigo 247 desta Constituição aplicar-se-á ao médico de Estado. 


\section{Personalidade Acadêmica Homenageada:}

\section{Augustus B. Cochran III (Agnes Scott College)}

A propositura da Câmara dos Deputados acrescenta, ainda, ao Ato das Disposições Constitucionais Transitórias, o artigo 96, com a seguinte redação: "Lei específica fixará remuneração inicial da carreira de médico de Estado em $\mathrm{R} \$ 15.187,00$ (quinze mil e cento e oitenta e sete reais), e a reajustará anualmente, de modo a preservar seu poder aquisitivo."

Trata-se, portanto, de uma medida que poderia corrigir as distorções apresentadas com a implantação do Programa Mais Médicos, alcançando os mesmos objetivos, de forma a garantir a presença dos médicos nas mais diversas localidades do território nacional, sem comprometer a segurança e os critério de habilitação.

Por outro lado, há que se pensar igualmente ações de governo que garantam não apenas o profissional, mas, com ele, ações que dêem uma infraestrutura mínima para que possam exercer o seu mister, de forma a garantir uma rede ampla de proteção à saúde, efetivando-se a garantia constitucional, nos termos traçados pelo nosso Sistema Único de Saúde.

\section{CONCLUSÃO}

Nosso paradigma de assistência à saúde ainda é bastante inócuo, com problemas que envolvem subfinanciamento e estrutura precária, com reflexos sobretudo nas atenções secundária (prestação de serviços especializados), terciária (procedimentos de alto custo) e hospitalar, além de vastas desigualdades regionais e carência de profissionais.

Logo, além de tratar da estratégia implementada pelo Programa Mais Médicos, bem como se a política pública é a mais eficaz e adequada à redução da distribuição de médicos pelo país e aumento do número de médicos por habitantes no Brasil, há que se investigar como a política atua na efetivação da garantia do acesso à saúde de forma ampla, bem como, a possibilidade de adoção de estratégias alternativas para atingir o mesmo objetivo traçado pelo Programa.

O diagnóstico específico do Programa aponta diversos problemas, conforme dados do Tribunal de Contas da União, tais como: ausência de monitoramento do 


\section{Personalidade Acadêmica Homenageada:}

\section{Augustus B. Cochran III (Agnes Scott College)}

cumprimento das cláusulas do termo de adesão e compromisso do Projeto Mais Médicos para o Brasil no que se refere à infraestrutura das Unidades de Saúde; o monitoramento deficitário da evolução quantitativa de médicos que atuam nos municípios participantes do Projeto Mais Médicos para o Brasil e o impacto nos resultados, considerando a substituição, pelas prefeituras, de médicos já contratados, por intercambistas/participantes; ausência de plena conferência do atendimento pelos médicos participantes dos critérios definidos para habilitação ao Projeto Mais Médicos para o Brasil, a saber: I - apresentar diploma expedido por instituição de educação superior estrangeira; II - apresentar habilitação para o exercício da Medicina no país de sua formação; e III - possuir conhecimento em língua portuguesa, regras de organização do SUS e protocolos e diretrizes clínicas no âmbito da Atenção Básica; inconformidades na utilização dos critérios de priorização da alocação dos médicos nos entes federativos; inconformidades na utilização dos critérios de priorização da alocação dos médicos nos entes federativos, considerando que percebeu-se que as vagas autorizadas foram em número menor, próximo à metade, das vagas solicitadas, não havendo clareza quanto aos critérios utilizados; realização de pagamentos indevidos e ausência de vinculação entre os pagamentos de bolsa formação aos médicos intercambistas individuais e médicos formados em instituições de ensino superior brasileiras e o cumprimento da carga horária; ausência de controles adequados e suficientes para a atestação da realização dos serviços constantes do Termo de Cooperação - TC 80 (OPAS - Médicos Cubanos), inclusive com pagamentos antecipados à OPAS sem a comprovação da prestação de serviços, com potencial prejuízo ao erário.

Neste contexto, garantir acesso à saúde passa por investimentos maciços e melhoria da atenção secundária e terciária, ao passo que a solução para a distribuição de médicos no país pode ser melhor alcançada por políticas públicas alternativas. Sendo assim, é possível que existam meios menos gravosos para obter a mesma proteção desejada, especialmente por meio de Propostas de Emenda à Constituição, em tramitação no Congresso Nacional, que prevêem a implantação da carreira médica nacional, apta a contratar profissionais por meio de concurso público e fixa-los obrigatoriamente em regiões mais longínquas, garantindo um plano de cargos e 
Personalidade Acadêmica Homenageada:

\section{Augustus B. Cochran III (Agnes Scott College)}

carreira em que possa ter mobilidade para regiões centrais ao longo da carreira, de maneira semelhante ao que ocorre com a Magistratura.

Logo, a presente pesquisa se propôs a abrir um norte investigatório crítico ao Programa Mais Médicos, sem esquecer da necessária problemática que o mesmo pretendeu resolver. Assim, abre um norte investigatório para que outras pesquisas surjam e proponham instrumentos adequados a solucionar o problema de maneira mais eficiente, sem olvidar de enxergar a garantia do acesso à saúde de forma holística, para além da mera presença física dos profissionais de saúde.

\section{REFERÊNCIAS}

ALMEIDA, P. F.; GIOVANELLA, L.; MENDONÇA, M. H.; ESCOREL, S. Desafios à coordenação dos cuidados em saúde: estratégias de integração entre níveis assistenciais em grandes centros urbanos. Caderno Saúde Pública 2010; 2:286-98.

BRAGA, José Carlos de Souza; PAULA, Sérgio Góes de. Saúde e previdência: estudos de política de saúde. Säo Paulo: Hucitec, 1986.

BRASIL. Câmara dos Deputados. Proposta de Emenda à Constituição 454/09. Altera o Título VIII, Capítulo II, Seção II - "Da Saúde” -, da Constituição da República Federativa do Brasil de 1988. Brasília: Câmara dos Deputados, 2009. $\overline{\text { jan } 2018 .}$

Conselho Federal de Medicina. Demografia Médica 2018. Brasília: CFM,

Constituição da República Federativa do Brasil. Brasília: Senado Federal - Centro Gráfico, 2018.

Lei no 3.268, de 30 de setembro de 1957. Dispõe sobre os Conselhos de Medicina, e dá outras providências. Brasília, set 1957.

Lei no 12.842, de 10 de julho de 2013. Dispõe sobre o exercício da Medicina. Brasília, jul 2013.

Lei no 12.871, de 22 de outubro de 2013. Institui o Programa Mais Médicos, altera as Leis no 8.745, de 9 de dezembro de 1993, e no 6.932, de 7 de julho de 1981, e dá outras providências. Brasília, out 2013. 
Personalidade Acadêmica Homenageada:

Augustus B. Cochran III (Agnes Scott College)

. Ministério da Saúde (MS). Secretaria de Gestão do Trabalho e da Educação na Saúde. Programa mais médicos - dois anos: mais saúde para os brasileiros. Brasília: MS, 2015.

Senado Federal. Proposta de Emenda à Constituição 140/2015. Altera o Título VIII, Capítulo II, Seção II - "Da Saúde" - da Constituição da República Federativa do Brasil de 1988. Brasília: Senado Federal, 2015.

Tribunal de Contas da União. ACÓRDÃo 1605/2015 - PLENÁRIO Solicitação do Congresso Nacional. Brasília: TCU, jul 2015.

. Tribunal de Contas da União. ACÓRDÃo 360/2017 - PLENÁRIO Acompanhamento do Programa Mais Médicos. Brasília: TCU, mar 2017.

DONNANGELO, Maria Cecília Ferro. Medicina e sociedade: O médico e seu mercado de trabalho. São Paulo, Pioneira, 1975.

ESCOREL. Sarah. Reviravolta na saúde: origem e articulação do movimento sanitário. Rio de Janeiro: Fiocruz, 1998.

FONSECA, Cristina M. Oliveira. Saúde no governo Vargas (1930-1945): dualidade institucional de um bem público. Rio de Janeiro: Fiocruz, 2007.

FRANÇA, Genival Veloso de. Direito médico. 14. Ed. Rio de Janeiro: Forense, 2017.

GIRARDI, S.; CARVALHO, C. L.; DER MASS, L. W.; FARAH, J.; ARAÚJO J. F. O trabalho em saúde: tendências e perspectivas na estratégia da Saúde da Família. Divulga Saúde Debate 2010; 45:11-25.

KOEN, Vincent. Public Expenditure Reform: The Health Care Sector in the United Kingdom. OECD Economics Department Working Papers, No. 256, OECD Publishing, 2000. Disponível em <http://dx.doi.org/10.1787/207823881077>. Acesso em 01 de outubro de 2018.

MACHADO, Roberto; LOUREIRO, Angela; LUZ, Rogerio; MURICY, Katia. Danação da norma: a medicina social e constituição da psiquiatria no Brasil. Rio de Janeiro: Edições Graal, 1978.

MOREIRA, K. S.; LIMA, C. A.; VIEIRA, M. A.; COSTA, S. M. Avaliação da infraestrutura das unidades de saúde da família e equipamentos para ações na atenção básica. In: Cogitare Enferm. (22)2: e51283, 2017.

PEREIRA, Lucélia Luiz et al. Projeto Mais Médicos para o Brasil: estudo de caso em comunidades quilombolas. Revista da ABPN 2015; 7(16):28-51. 
Personalidade Acadêmica Homenageada:

Augustus B. Cochran III (Agnes Scott College)

POSSAS, Cristina de Albuquerque. Saúde e trabalho: A crise da previdência social. Rio de Janeiro: Edições Graal, 1981.

SINGER, Paul; CAMPOS, Oswaldo; OLIVEIRA, Elizabeth M. de. Prevenir e curar: O controle social através dos serviços de saúde. Rio de Janeiro: Forense Universitária, 1988.

TEIXEIRA, Sônia Maria Fleury. O dilema da reforma sanitária brasileira. In: BERLINGUER, G.; TEIXEIRA, S. M. F.; CAMPOS, G. W. S. (org.). Reforma sanitária Itália e Brasil. São Paulo: Hucitec/Cebes, 1988. 